\title{
Socioeconomic status is associated with reduced lung function in China: an analysis from a large cross-sectional study in Shanghai
}

\author{
Adam W. Gaffney ${ }^{1 *}$, Jing-qing Hang ${ }^{2}$, Mi-Sun Lee ${ }^{3}$, Li Su³ ${ }^{3}$ Feng-ying Zhang ${ }^{2}$ and David C. Christiani ${ }^{1,3,4}$
}

\begin{abstract}
Background: An inverse association between socioeconomic status and pulmonary function has emerged in many studies. However, the mediating factors in this relationship are poorly understood, and might be expected to differ between countries. We sought to investigate the relationship between socioeconomic status and lung function in China, a rapidly industrializing nation with unique environmental challenges, and to identify potentially-modifiable environmental mediators.

Methods: We used data from the Shanghai Putuo Study, a cross-sectional study performed in Shanghai, China. Participants completed a questionnaire and spirometry. The primary exposure was socioeconomic status, determined by education level. The primary outcomes were $\mathrm{FEV}_{1}$ and $\mathrm{FVC}$ percent predicted. Multiple linear regressions were used to test this association, and the percent explained by behavioral, environmental, occupational, and dietary variables was determined by adding these variables to a base model.

Results: The study population consisted of a total of 22,878 study subjects that were $53.3 \%$ female and had a mean age of 48. In the final multivariate analysis, the effect estimates for $\mathrm{FEV}_{1}$ and FVC percent predicted for low socioeconomic status (compared to high) were statistically significant at a p-value of $<0.01$. Smoking, biomass exposure, mode of transportation to work, a diet low in fruits or vegetables, and occupational category partially attenuated the relationship between SES and lung function. In a fully-adjusted age-stratified analysis, the socioeconomic disparity in lung function widened with increasing age.
\end{abstract}

Conclusions: We found cross-sectional evidence of socioeconomic disparities in pulmonary function in Shanghai. These differences increased with age and were partially explained by potentially modifiable exposures.

Keywords: Socioeconomic factors, Respiratory disease, Environmental health, Epidemiology, China, Pulmonary function

\section{Background}

An inverse association between socioeconomic status (SES) and lung function has been described in the epidemiological literature for decades [1]. Whether SES is measured by individual education [2-7], parental status [8], income [3], occupation [2, 9], or residential area deprivation [2], a social gradient in pulmonary function emerges in most studies.

\footnotetext{
* Correspondence: agaffney@mgh.harvard.edu

'Massachusetts General Hospital, 55 Fruit Street, Boston, MA 02114, USA

Full list of author information is available at the end of the article
}

However, the pathways through which low SES cause reduced lung function remain obscure. In one review, Hegewald and Crapo propose a number of putative factors linking SES and pulmonary function, including prenatal exposures, air pollution, nutritional factors, and occupational exposures [1]. Most likely, a multitude of environmental intermediaries plays a role in the complex relationship between SES and lung function [9]. Additionally, it is plausible that environmental factors are locationspecific and differ among high, middle, and low-income countries, which contend with diverse environmental health challenges. 
The majority of studies to date on this topic, however, have been performed in high-income countries [1]. While some studies have been performed in low and middle-income countries $[10,11]$, fewer have been performed in China, a rapidly industrializing nation [12] with unique environmental hazards and a large burden of respiratory disease [13]. For instance, though some studies have identified an association between education and airflow obstruction in China [14-16], we are not aware of any studies that have sought to identify environmental mediators between SES and lung function in China. Given the association between reductions in pulmonary function and mortality $[17,18]$, identification of these potentially modifiable mediators could have significant public health implications.

We therefore undertook this study using data from the Shanghai Putuo Cohort Study, a large scale populationbased cross-sectional study in Shanghai, China to investigate the impact of SES on lung function in Shanghai, and to consider a number of environmental, occupational, and dietary exposures as potential mediators in this relationship.

\section{Methods}

\section{Study design and data collection}

The Shanghai Putuo study is a population-based crosssectional study performed in Shanghai, China. It is a collaboration between the Harvard School of Public Health and the Shanghai District Peoples Hospital. The Institutional Review Boards of both institutions approved the study (Harvard T.H. Chan School of Public Health IRB Protocol \#CR-14777-01). The design of the study has been previously published in detail [19-21], but is briefly summarized here. Study subjects were recruited on the basis of random selection using census tract data between August 2007 and January 2010. There were no exclusion criteria. Subjects were questioned in person by interviewers who were trained and tested in the administration of the study questionnaire. These questionnaires included a wide range of social, demographic, occupational, environmental, and dietary queries.

For SES, our primary exposure of interest, we used education instead of current income in order to reduce the problem of reverse causality. Education was selfreported by study participants ("illiterate" (1), "primary" (2), "junior middle school" (3), "senior middle school" (4), "senior training school and high school" (5), and "college or above" (6)). This was simplified into a three category variable that approximates educational strata in the United States: (A) low: levels 1 to 3 (extending up to children age 13), (B) intermediate: levels 4-5 (typically ages 13-18), and (C) high: level 6 (ages 18+).

A total of 37,690 subjects were selected at random for recruitment. Of these, 27,042 agreed to participate in the study and provided written consent (see Fig. 1). Information on gender and age $(<18$ or $\geq 18)$ were available on some (7291 of 10,648$)$ of those who declined to participate. Of these, 7016 individuals were $\geq 18$ years, and of these $3713(52.9 \%)$ were male and 3303 (47.1\%) were female. Of the 27,042 participants, 1819 were less than 18 years of age and were excluded. Of the remaining subjects, 1091 had missing spirometry and were excluded. An additional 380 subjects with high withinsubject variability as assessed by a coefficient of variation for FVC of greater than $20 \%$ were also excluded. Of the remaining subjects, 874 had missing covariate data, and were excluded. This left a total of 22,878 subjects, or $84.6 \%$ of the parent study population of 27,042 , for our final analysis.

\section{Spirometry}

Measurement of $\mathrm{FEV}_{1}$ and $\mathrm{FVC}$ was performed according to American Thoracic Society guidelines [22] by a trained technician using a hand-held spirometer (Micro plus, Micro Ltd., Rochester UK) as previously described [19]. Subjects performed spirometry while in a sitting position. All study subjects performed at least three efforts, and the highest $\mathrm{FEV}_{1}$ and FVC was used from these measurements. To be considered acceptable, the FVC had to be sustained for no less than six seconds. In order to assess for within-subject variability, we calculated a coefficient of variation $(\mathrm{CV})$ using the standard deviation of the FVC divided by its mean $\times 100$. A CV of $20 \%$ or less was considered acceptable, a threshold that has been used in other studies [19, 23, 24]. As described

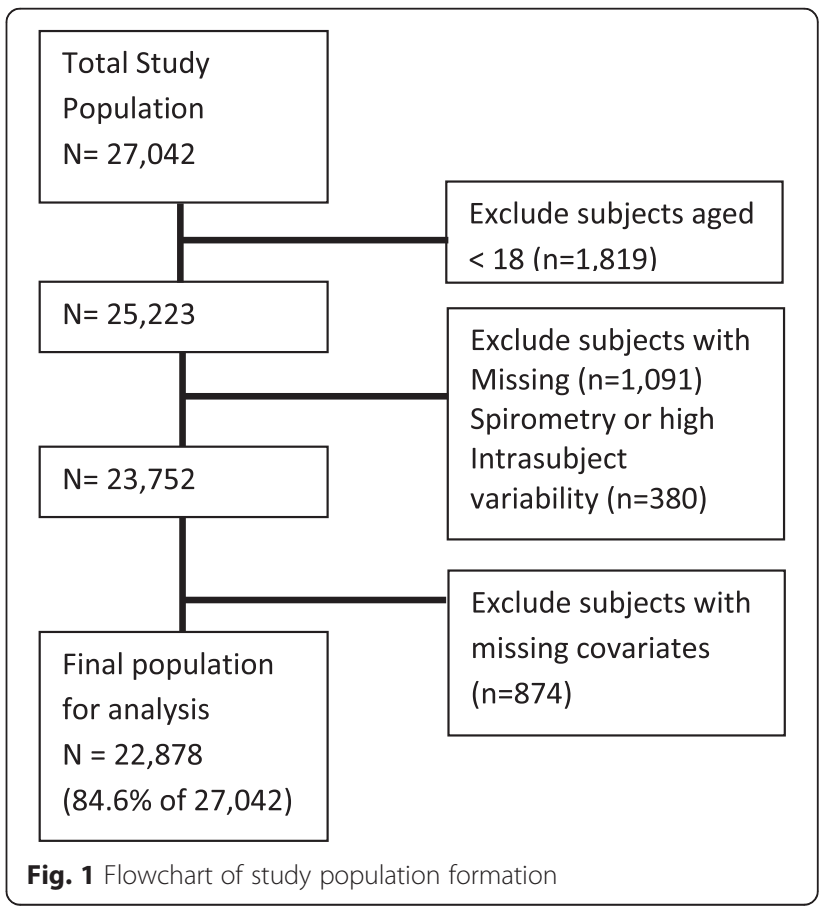


above, subjects that did not meet this threshold were subsequently excluded from our analysis. We used a validated prediction equation for the adult Chinese population to calculate the $\mathrm{FEV}_{1}$ and $\mathrm{FVC}$ percent predicted for each study subject [25].

\section{Statistical analysis}

The primary outcome measures were $\mathrm{FEV}_{1}$ percent predicted and FVC percent predicted. The primary exposure was SES, which was treated as a categorical variable as described above. We additionally selected covariates for inclusion in our model which we posited might function as putative intermediaries between SES and lung function. Smoking was treated both as a categorical variable (current, former, or never) and in pack-years of smoking history. Second-hand smoke exposure (SHS) and home biomass exposure were treated as binary variables (ever versus never exposed). Subjects were considered exposed to biomass if they reported any previous exposure to solid fuels (which included coal and/or biomass) for cooking and/or heating in the home. Mode of transportation to work, which has been associated with lung function in this study population in work by our group [21], was treated as a categorical variable (bus without air conditioning, bus with air conditioning, bicycle, scooter, taxi, company car, private care, train, subway, walking, none, or multiple forms). A diet low in fruit or vegetable consumption ( $<1$ serving/daily in either (a) fruits or in (b) both cooked and raw vegetables) was used as a surrogate for low-antioxidant consumption, which has been associated with reduced lung function [26]. Occupational status was treated as a categorical variable (farmer, worker, professional, administrator, services, household, retired, other). Though we conceived of these variables as potential mediators, it is possible that they may also function as confounders or as markers of SES.

All statistical analyses were performed using SAS Version 9.4 (SAS Institute Inc,.Carry, NC, USA). The approach to model building and the assessment of environmental covariates as potential mediators of the SES-lung function relationship drew on two previous investigations on this subject [5,9]. In Model 0 , we evaluated the relationship of SES to $\mathrm{FEV}_{1}$ and $\mathrm{FVC}$ percent predicted using linear regression. $\mathrm{FEV}_{1}$ percent predicted and FVC percent predicted were not adjusted for age or gender because the regression models used to calculate these values are already age and gender adjusted. However, we did perform a sensitivity analysis including additional adjustment for age and gender to ensure the robustness of our final model. We added the personal smoking variables to Model 0 to form Model 1. We subsequently added covariates to Model 1 to assess the degree to which each exposure attenuated the SES-lung function relationship after adjustment for smoking. To Model 1, we added SHS exposure (Model 2), home biomass use (Model 3), mode of commuting (Model 4), low fruit/ vegetable consumption (Model 5), occupational status (Model 6), and all of these covariates (Model 7). The percent explained by a given exposure was calculated by taking the difference in the effect estimate of SES between the base model and a model with an added covariate(s), and then dividing this by the effect estimate of the base model $[9,27]$. Model 1 was compared to model 0 , whereas models 2-7 were compared to model 1 . Additionally, we looked for linear trends in the SES-lung function relationship in each model by treating SES as a continuous variable.

To assess effect modification by age and gender, multiplicative interaction terms along with the main effects were added to the final model. Given evidence that the SES-lung function relationship may differ by age group (18-39, 40-64, $\geq 65$ years) [9], we assessed the degree to which age modifies the SES-lung function relationship by testing for an age category (18-39, 40-64, $\geq 65$ years)-SES interaction (for this model, SES was treated as continuous). We also performed analyses using our final model stratified by gender and by age category.

\section{Results}

Characteristics of the study population, stratified by SES, are shown in Table 1 . The study population had a mean age of 48 and was $53.3 \%$ female. A socioeconomic gradient in several baseline characteristics emerged. As SES increased, values for the following variables decreased: mean age; percent female; percent with low fruit/vegetable consumption; percent ever exposed to biomass fuel; pack years of smoking history; the percent walking, biking, or taking a bus without air-conditioning to work; and the percent with retired, household duties, or "worker" occupational categories. Percent commuting via private car and the percent working as a "professional" or "administrator" increased with higher SES. The percent currently smoking, the percent occupied in "services," and the percent with a history of SHS exposure was similar in the low and intermediate education groups but lower in the high SES group.

The unadjusted effect estimates of $\mathrm{FEV}_{1}$ and FVC percent predicted ("Model 0") is shown in Fig. 2. Low education, as compared with high education, was associated with a 3.33 reduction in $\mathrm{FEV}_{1}$ percent predicted (95\% CI $-3.93,-2.73)$ and an 8.13 reduction in FVC percent predicted $(-8.71,-7.54)$. Intermediate education, as compared with high education, was associated with a 0.79 reduction in $\mathrm{FEV}_{1}$ percent predicted $(95 \% \mathrm{CI}-1.37,-0.21)$ and a 2.72 reduction in FVC percent predicted (95\% CI $-3.29,-2.16$ ).

The results of the multivariate analysis are demonstrated in Table 2. The effect estimates for $\mathrm{FEV}_{1}$ and FVC percent 
Table 1 Characteristics of the study population, stratified by SES $(n=22,878), n(\%)$ or mean \pm SD

\begin{tabular}{|c|c|c|c|c|}
\hline & \multirow[b]{2}{*}{ Total Population } & \multicolumn{3}{|c|}{ Education Level } \\
\hline & & elementary & middle/high & college \\
\hline Subjects, n (\%) & $22,878(100)$ & $8375(36 \cdot 6)$ & $10,351(45 \cdot 2)$ & $4152(18 \cdot 2)$ \\
\hline Age, years & $48 \cdot 4 \pm 16 \cdot 4$ & $58 \cdot 5 \pm 13 \cdot 3$ & $44 \cdot 9 \pm 14 \cdot 6$ & $36 \cdot 8 \pm 15 \cdot 1$ \\
\hline Female & $12,195(53 \cdot 3)$ & $5048(60 \cdot 3)$ & $5339(51 \cdot 6)$ & $1808(43 \cdot 6)$ \\
\hline \multicolumn{5}{|l|}{ Smoking } \\
\hline Current & $5249(22 \cdot 9)$ & $2028(24 \cdot 2)$ & $2636(25 \cdot 5)$ & $585(14 \cdot 1)$ \\
\hline Former & $878(3 \cdot 8)$ & $439(5 \cdot 2)$ & $349(3 \cdot 4)$ & $90(2 \cdot 2)$ \\
\hline Never & $16,751(73 \cdot 2)$ & $5908(70 \cdot 5)$ & $7366(71 \cdot 2)$ & $3477(83 \cdot 7)$ \\
\hline Pack-years ${ }^{a}$ & $26 \cdot 3 \pm 36 \cdot 6$ & $32 \cdot 3 \pm 42 \cdot 5$ & $23 \cdot 3 \pm 31 \cdot 6$ & $17 \cdot 9 \pm 30 \cdot 0$ \\
\hline SHS exposed & $17,060(74 \cdot 6)$ & $6492(77 \cdot 5)$ & $7976(77 \cdot 1)$ & $2592(62 \cdot 4)$ \\
\hline Biomass ever users & $18,214(79 \cdot 6)$ & $7799(93 \cdot 1)$ & $8056(77 \cdot 8)$ & $2359(56 \cdot 8)$ \\
\hline Low fruit/vegetable & $13,683(59 \cdot 8)$ & $5876(70 \cdot 2)$ & $5886(56 \cdot 9)$ & $1921(46 \cdot 3)$ \\
\hline \multicolumn{5}{|l|}{ Mode of Transport } \\
\hline None & $8(0 \cdot 0)$ & $6(0 \cdot 1)$ & $0(0 \cdot 0)$ & $2(0 \cdot 1)$ \\
\hline Bus w/o AC & $2950(12 \cdot 9)$ & $1157(13 \cdot 8)$ & $1323(12 \cdot 8)$ & $470(11 \cdot 3)$ \\
\hline Bus with AC & $3665(16 \cdot 0)$ & $696(8 \cdot 3)$ & $2011(19 \cdot 4)$ & $958(23 \cdot 1)$ \\
\hline Scooter & $2628(11 \cdot 5)$ & $691(8 \cdot 3)$ & $1554(15 \cdot 0)$ & $383(9 \cdot 2)$ \\
\hline Taxi & $128(0 \cdot 6)$ & $27(0 \cdot 3)$ & $70(0 \cdot 7)$ & $31(0 \cdot 8)$ \\
\hline Company Car & $330(1 \cdot 4)$ & $57(0 \cdot 7)$ & $189(1 \cdot 8)$ & $84(2 \cdot 0)$ \\
\hline Private Car & $1916(8 \cdot 4)$ & $168(2 \cdot 0)$ & $929(9 \cdot 0)$ & $819(19 \cdot 7)$ \\
\hline Train & $18(0 \cdot 1)$ & $0(0 \cdot 0)$ & $10(0 \cdot 1)$ & $8(0 \cdot 2)$ \\
\hline Subway & $138(0 \cdot 6)$ & $5(0 \cdot 1)$ & $59(0 \cdot 6)$ & $74(1 \cdot 8)$ \\
\hline Walk & $3219(14 \cdot 1)$ & $2246(26 \cdot 8)$ & $800(7 \cdot 7)$ & $173(4 \cdot 2)$ \\
\hline Multiple & $2709(11 \cdot 8)$ & $693(8 \cdot 3)$ & $1247(12 \cdot 1)$ & $769(18 \cdot 5)$ \\
\hline Bike & $5169(22 \cdot 6)$ & $2629(31 \cdot 4)$ & $2159(20 \cdot 9)$ & $381(9 \cdot 2)$ \\
\hline \multicolumn{5}{|l|}{ Occupation } \\
\hline Farmer & $110(0.5)$ & $102(1.2)$ & $8(0.1)$ & $0(0.0)$ \\
\hline Worker & $1405(6.1)$ & $689(8.2)$ & $696(6.7)$ & $20(0.5)$ \\
\hline Professional & $5128(22.4)$ & $595(7.1)$ & $2636(25.5)$ & $1897(45.7)$ \\
\hline Administrator & 2969 (13.0) & $276(3.3)$ & $1688(16.3)$ & 1005 (24.2) \\
\hline Services & $1526(6.7)$ & $556(6.6)$ & 909 (8.8) & $61(1.5)$ \\
\hline Household & 368 (1.6) & $206(2.5)$ & 145 (1.4) & $17(0.4)$ \\
\hline Retired & 9130 (39.9) & $5443(65.0)$ & 3129 (30.2) & $558(13.4)$ \\
\hline Other & $2242(9.8)$ & $508(6.1)$ & 1140 (11.0) & $594(14.3)$ \\
\hline$\% \mathrm{FEV}_{1}$ & $97 \cdot 8 \pm 16 \cdot 3$ & $96 \cdot 1 \pm 18 \cdot 6$ & $98 \cdot 6 \pm 14 \cdot 9$ & $99 \cdot 4 \pm 14 \cdot 0$ \\
\hline$\%$ FVC & $89 \cdot 3 \pm 16 \cdot 1$ & $85 \cdot 4 \pm 17 \cdot 5$ & $90 \cdot 8 \pm 14 \cdot 8$ & $93 \cdot 5 \pm 14 \cdot 4$ \\
\hline
\end{tabular}

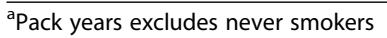

predicted for low SES (as compared to high) were negative and statistically significant at $p<0.01$ for all models. Additionally, a test for trend (treating SES as a continuous variable) for both $\mathrm{FEV}_{1}$ and $\mathrm{FVC}$ percent predicted was significant at $P<0.01$ for all models. As seen in Table 2, with the exception of SHS, each of the added covariates explained part of the effect of low education on $\mathrm{FEV}_{1}$ and/or FVC percent predicted. However, after adjustment for smoking, intermediate education no longer had a significant effect on $\mathrm{FEV}_{1}$ percent predicted, and so the "percent explained" for those effect estimates have little meaning; the same is true for the effect of intermediate education on FVC percent predicted in the final model. For the effect of low education on $\mathrm{FEV}_{1}$ percent predicted, occupational category had the largest percent explained, followed by smoking, mode of transport, and low 


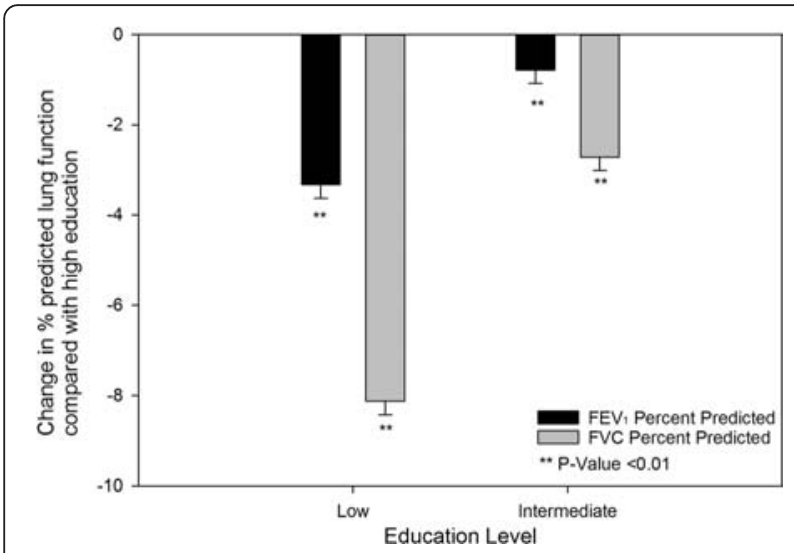

Fig. 2 Unadjusted estimates of FEV1 and FVC percent predicted associated with educational level

fruit/vegetable diet. For the effect of low education on FVC percent predicted, occupational category also had the largest percent explained, followed by mode of transport, biomass exposure, smoking, and finally low fruit/vegetable exposure. For both $\mathrm{FEV}_{1}$ and FVC percent predicted, the final model with all covariates included had the greatest percent explained. The final model explained $39 \%$ of the smoking-adjusted reduction in $\mathrm{FEV}_{1}$ percent predicted, and $60 \%$ of the smoking-adjusted reduction in FVC percent predicted, that was associated with low education. Of note, in a sensitivity analysis that was additionally adjusted for age and gender, the effect of low education (as compared to high education) on both $\mathrm{FEV}_{1}$ and $\mathrm{FVC}$ percent predicted was still significant at a p-value $<0.01$ in the final model (data not shown).

Finally, to assess whether the SES-lung function relationship differs across age groups and between genders, the fully adjusted analysis was repeated stratified by age category (Table 3 ) and by gender (Table 4). The test for trend for the effect of SES on lung function remained significant $(P<0.01)$ for both $\mathrm{FEV}_{1}$ and $\mathrm{FVC}$ percent predicted for both genders and in all age categories, with the exception of $\mathrm{FEV}_{1}$ percent predicted in those aged $<40$. The effect of SES on lung function differed both by gender and by age category. In the stratified analysis, a clear gradient in terms of the effect of SES on lung function emerged across the age categories, with a widening in the socioeconomic differential in lung function with increasing age. We found statistically significant effect modification by age category when interaction terms with main effects were added to the final model: the effect of SES on both FEV 1 and FVC percent predicted was greater for those age $>=65$ as compared to both those under 40 years $(P$ for interaction $<0.01$ ) and those age $40-64$ years old ( $P$ for interaction $<0.01$ ). We also found effect modification by gender. The deleterious effects of low
SES on lung function were greater among men than women in the stratified analysis, and we found that the difference between men and women was statistically significant for both $\mathrm{FEV}_{1}$ and $\mathrm{FVC}$ percent predicted $(P$ for interaction $<0.01)$.

\section{Discussion}

In this study, we found evidence for a socio-economic gradient in pulmonary function in an adult Chinese population. We were able to partially explain this association on the basis of several modifiable environmental factors, and we additionally found that the magnitude of the disparities became larger with increasing age. Together, these findings further strengthen long-standing evidence of an SES-lung function relationship, demonstrate that this relationship holds for an adult population in Shanghai across the life course, and suggest that specific life-long environmental factors may possibly play a mediating role.

A relationship between lung function and SES has long been observed. A 2007 review, drawing on 20 studies together involving 125,253 adults and 18,477 children, concluded that SES was an important and underappreciated risk factor for reduced lung function in many countries [1]. While smoking contributes to this relationship, it is "only one piece of the puzzle," necessitating further investigation into mediating risk factors [1-3]. Outdoor air pollution, indoor air pollution, environmental tobacco exposure, and diet are some additional putative modifiable risk factors. SHS exposure, for instance, emerged as a potential mediator in the SES-lung function relationship among some subgroups in one study [9]. Low SES is also associated with increased exposure to poor outdoor air quality, which could also potentially explain some of the SES-lung function relationship [28]. One study found attenuation in the SES-lung function association after controlling for PM10, something we were unable to do in this study [5]. Dietary factors are another potential mediator given the association between anti-oxidant consumption and lung function $[26,29,30]$. Some have found an attenuation of the SES-lung function relationship when adjusting for vitamin $\mathrm{C}$ intake [31], though others have found no mediating effect from low fruit and vegetable consumption [6].

In our study, only some of the SES-lung function relationship was explained by smoking, and, after adjusting for smoking, none was explained by SHS exposure. Occupational category subsequently explained the most of the SES-lung function relationship among the investigated variables. We should note, however, that while this may in part result from differential exposures in the workplace, it may also result from the fact that occupation is itself another index of SES. Some of the "percent explained" of occupation may therefore reflect better 
Table 2 Adjusted estimates for percent predicted $\mathrm{FEV}_{1}$ and FVC associated with education level

\begin{tabular}{|c|c|c|c|c|c|c|c|}
\hline \multirow[b]{2}{*}{ Model } & \multirow[b]{2}{*}{ Education } & \multicolumn{3}{|l|}{$\mathrm{FEV}_{1} \%$ Predicted } & \multicolumn{3}{|l|}{ FVC \% Predicted } \\
\hline & & Effect Estimate (95 \% Cl) & $\begin{array}{l}\text { Estimate } \\
\text { P-value }\end{array}$ & $\%$ explained & Effect Estimate (95\% Cl) & $\begin{array}{l}\text { Estimate } \\
\text { P-value }\end{array}$ & $\%$ explained \\
\hline \multirow[t]{4}{*}{ 1: Adjusted for smoking } & Low & $2.53(3.13,1.94)$ & $<.01$ & $24 \%$ & $7.29(7.88,6.71)$ & $<.01$ & $10 \%$ \\
\hline & Intermediate & $0.21(0.79,0.37)$ & 0.48 & $74 \%$ & $2.13(2.69,1.57)$ & $<.01$ & $22 \%$ \\
\hline & High & Reference & & & Reference & . & \\
\hline & Trend Test P-Value & $<.01$ & & & $<.01$ & & \\
\hline \multirow[t]{4}{*}{ 2: Model 1 adjusted for SHS } & Low & $2.59(3.20,1.99)$ & $<.01$ & $2 \%$ & $7.37(7.96,6.79)$ & $<.01$ & $-1 \%$ \\
\hline & Intermediate & $0.27(0.85,0.32)$ & 0.37 & $27 \%$ & $2.20(2.77,1.64)$ & $<.01$ & $4 \%$ \\
\hline & High & Reference & . & & Reference & . & \\
\hline & Trend Test P-Value & $<.01$ & & & $<.01$ & & \\
\hline \multirow{4}{*}{$\begin{array}{l}\text { 3: Model } 1 \text { adjusted for } \\
\text { biomass }\end{array}$} & Low & $2.49(3.12, \quad 1.87)$ & $<.01$ & $2 \%$ & $6.31(6.92, \quad 5.70)$ & $<.01$ & $14 \%$ \\
\hline & Intermediate & $0.19(0.78,0.40)$ & 0.54 & $11 \%$ & $1.56(2.13,0.99)$ & $<.01$ & $27 \%$ \\
\hline & High & Reference & . & & Reference & & \\
\hline & Trend Test P-Value & $<.01$ & & & $<.01$ & & \\
\hline \multirow{4}{*}{$\begin{array}{l}\text { 4: Model adjusted for mode } \\
\text { of transport }\end{array}$} & Low & $1.99(2.64,1.33)$ & $<.01$ & $22 \%$ & $5.36(5.99,4.73)$ & $<.01$ & $26 \%$ \\
\hline & Intermediate & $0.04(0.63,0.55)$ & 0.90 & $82 \%$ & $1.45(2.02,0.88)$ & $<.01$ & $32 \%$ \\
\hline & High & Reference & . & & Reference & & \\
\hline & Trend Test P-Value & $<.01$ & & & $<.01$ & & \\
\hline \multirow{4}{*}{$\begin{array}{l}\text { 5: Model } 1 \text { adjusted for low } \\
\text { fruit/veg }\end{array}$} & Low & $2.29(2.89,1.68)$ & $<.01$ & $10 \%$ & $6.86(7.45,6.28)$ & $<.01$ & $6 \%$ \\
\hline & Intermediate & $0.11(0.69,0.47)$ & 0.70 & $45 \%$ & $1.96(2.53,1.40)$ & $<.01$ & $8 \%$ \\
\hline & High & Reference & . & & Reference & . & \\
\hline & Trend Test P-Value & $<.01$ & & & $<.01$ & & \\
\hline \multirow{4}{*}{$\begin{array}{l}\text { 6: Model } 1 \text { adjusted for } \\
\text { occupation }\end{array}$} & Low & $1.82(2.51,1.13)$ & $<.01$ & $28 \%$ & $4.05(4.72,3.39)$ & $<.01$ & $44 \%$ \\
\hline & Intermediate & $0.07(0.54,0.67)$ & 0.83 & $131 \%$ & $0.93(1.51, \quad 0.35)$ & $<.01$ & $56 \%$ \\
\hline & High & Reference & . & & Reference & . & \\
\hline & Trend Test P-Value & $<.01$ & & & $<.01$ & & \\
\hline \multirow[t]{4}{*}{ 7: All Covariates } & Low & $1.55(2.27, \quad 0.82)$ & $<.01$ & $39 \%$ & $2.93(3.62, \quad 2.24)$ & $<.01$ & $60 \%$ \\
\hline & Intermediate & $0.09(0.53,0.70)$ & 0.78 & $142 \%$ & $0.52(1.11,0.07)$ & 0.08 & $76 \%$ \\
\hline & High & Reference & & & Reference & . & \\
\hline & Trend Test P-Value & $<.01$ & & & $<.01$ & & \\
\hline
\end{tabular}

Percent explained is the equal to percent reduction in the effect estimate. Model 1 is compared to model 0, and models 2-7 are compared to model 1 (e.g. \%

explained for model $7=$ [model 1 effect estimate - model 7 effect estimate]/model 1 effect estimate). Prediction equations are from an adult Chinese population [25]

adjustment for SES. This may be true, to some extent, of the other covariates, which may function as intermediaries but also as potential confounders or markers of SES. Notably, we also found that a fruit/vegetable deficient diet explained a small part of the relationship. However, perhaps the most novel finding was the identification of mode of transportation to work and exposure to indoor air pollution (biomass exposure) as two important possible mediating factors. These are both plausible mediators from the biological perspective. Biomass use, for instance, is associated with reduced lung function, perhaps in part through the induction of oxidative stress [19]. Commuting exposures, on the other hand, has been associated with varying levels of exposure to ambient pollutants depending on vehicle utilized [32, 33], and has also been associated with adverse short-term respiratory effects [34-36]. Work by our group in this cohort found a relationship between mode of commuting and pulmonary function [21]. However, it is unclear to what extent these differences reflect varying exposure to pollution, routes used, the impact of exercise on minute ventilation and inhaled dose of particles, or other factors.

An unresolved question is the relative importance of prenatal, childhood, and adult exposures in mediating the SES-lung function relationship. For instance, factors affecting intrauterine growth likely have an impact on postnatal lung function [37]. Additionally, when looking at $\mathrm{FEV}_{1}$ and $\mathrm{FVC}$ in absolute terms (instead of percent predicted), a significant part of the SES-lung function relationship can be explained by the socioeconomic 
Table 3 Adjusted estimates for percent predicted $\mathrm{FEV}_{1}$ and FVC associated with education level stratified by age category

\begin{tabular}{|c|c|c|c|c|c|}
\hline & & FEV1 \% Predicted ${ }^{a}$ & & FVC \% Predicted $^{a}$ & \\
\hline & & Estimate $(95 \% \mathrm{Cl})$ & P-value & Estimate $(95 \% \mathrm{Cl})$ & P-value \\
\hline Age $<40$ & Low & $0.82(2.01,0.37)$ & 0.18 & $1.34(2.58,0.10)$ & 0.03 \\
\hline & Intermediate & $0.58(-1.25,0.09)$ & 0.09 & $0.77(1.47,0.08)$ & 0.03 \\
\hline & High & Reference & . & Reference & \\
\hline & Trend test $\mathrm{p}$-value & & 0.08 & & 0.01 \\
\hline Age $40-64$ & Low & $1.85(3.05,0.66)$ & $<0.01$ & $2.23(3.39,1.08)$ & $<0.01$ \\
\hline & Intermediate & $0.64(1.77,0.49)$ & 0.27 & $0.81(1.91,0.28)$ & 0.14 \\
\hline & High & Reference & . & Reference & . \\
\hline & Trend test $p$-value & & $<0.01$ & & $<0.01$ \\
\hline Age 65 & Low & $4.76(7.33, \quad 2.20)$ & $<0.01$ & $5.50(7.60,3.40)$ & $<0.01$ \\
\hline & Intermediate & $1.65(4.39,1.09)$ & 0.24 & $1.42(3.67,0.82)$ & 0.21 \\
\hline & High & Reference & & Reference & . \\
\hline & Trend test $p$-value & & $<0.01$ & & $<0.01$ \\
\hline
\end{tabular}

${ }^{a}$ Adjusted for SHS exposure (yes or no), smoking history (current, former, and never), pack years of smoking, biomass exposure (yes or no), low fruit/vegetable diet $(<1 /$ day serving of either fruits or vegetables), mode of transport to work, and occupational category

gradient in height, itself the result of early-life exposures, which in turn directly impacts lung function [9, 31]. Social factors in early life may also modify the effect of environmental exposures. For instance, the effect of traffic-related air pollution on lung function may be amplified in households exposed to high levels of stress [38, 39]. However, if the SES-lung function relationship was predominantly the result of intrauterine or childhood exposures, we might expect that the strength of the relationship would either remain stable or be attenuated with increasing age. Conversely, in a recent large crosssectional study in Scotland, Gray et al. found that the SESgradient in $\mathrm{FEV}_{1}$ actually became larger with increasing age [9]. Our results in this study are consistent with the findings of Gray et al. In stratifying our analysis across the same age categories as Gray et al., we also found that social disparities in lung function widened as age increased, suggesting that ongoing environmental exposures might have a continuing impact on lung function throughout life. An alternative explanation for this finding is that SES was more a determinant of lung function for older cohorts than for younger ones, and therefore reflects the impact of undefined secular environmental trends. However, this would imply analogous secular trends playing out over time in both Scotland and China, which seems less likely. Notably, we also found evidence for effect modification by gender, such that the deleterious effect of low SES on lung function was greater among men than women. We speculate that this could relate to the fact that certain exposures (for instance, in the workplace) may be more associated with low education in men than among women.

We acknowledge some limitations to this study, most notably the cross-sectional design, which prevents us from drawing clear conclusions with respect to causality. However, by using education as a metric for SES, the likelihood of reverse causality is reduced. For instance, the onset of respiratory disease during adulthood could result in reduced SES when measured by current

Table 4 Adjusted estimates for percent predicted FEV 1 and FVC associated with education level stratified by gender

\begin{tabular}{|c|c|c|c|c|c|}
\hline \multirow[b]{3}{*}{ Female } & \multirow[b]{3}{*}{ Low } & \multicolumn{2}{|l|}{ FEV1 \% Predicted ${ }^{\mathrm{a}}$} & \multicolumn{2}{|l|}{ FVC \% Predicted ${ }^{a}$} \\
\hline & & Estimate (95 \% Cl) & P-value & Estimate $(95 \% \mathrm{Cl})$ & P-value \\
\hline & & $2.61(3.70,1.52)$ & $<0.01$ & $3.63(4.67,2.59)$ & $<0.01$ \\
\hline \multirow[t]{3}{*}{$(n=12,195)$} & Intermediate & $0.70(1.63,0.23)$ & 0.14 & $1.16(2.05,0.27)$ & 0.01 \\
\hline & High & Reference & & Reference & \\
\hline & Trend test $p$-value & & $<0.01$ & & $<0.01$ \\
\hline Male & Low & $3.66(4.63,2.69)$ & $<0.01$ & $5.49(6.41,4.57)$ & $<0.01$ \\
\hline \multirow[t]{3}{*}{$(n=10,683)$} & Intermediate & $1.06(1.87,0.24)$ & 0.01 & $1.93(2.70,1.15)$ & $<0.01$ \\
\hline & High & Reference & & Reference & \\
\hline & Trend test $p$-value & & $<0.01$ & & $<0.01$ \\
\hline
\end{tabular}

${ }^{a}$ Adjusted for SHS exposure (yes or no), smoking history (current, former, and never), pack years of smoking, biomass exposure (yes or no), low fruit/vegetable diet $(<1 /$ day serving of either fruits or vegetables), mode of transport to work, and occupational category 
income, but not when measured by previously attained education. Of course, it is possible that children with lung disease might be less likely to pursue higher education. However, if this were the explanation for our findings, we would not expect to see a widening socioeconomic gradient in lung function in older age groups. Additionally, it is worth mentioning that 10,648 individuals declined to participate in the study. It is possible that these individuals differed from those who participated. Notably, a majority of those who declined who were age 18 or over were male, whereas our study population was majority female. This could potentially reflect differing availability to participate given job responsibilities. It is also possible that those who declined may have been of a lower SES (given that written consent was required as part of the study). Even if this were the case, we would expect that the relationship between low SES and reduced lung function in these subjects would be similar to the relationship between low SES and reduced lung function in our overall study population. Thus, we would expect that the exclusion of these individuals would only bias our study towards the null. Other potential weaknesses relate to the subjective determination of indoor air pollution, the imprecision of our dietary variable, the lack of information on area level SES, and the lack of data on levels of outdoor or workplace air pollution. It is also important to again emphasize that the covariates we treated as potential mediating factors may actually be functioning as confounders, or - especially in the case of occupation - as markers of SES.

We also recognize several strengths of this study, including its large size and the objective outcome measurement. Additionally, the SES-lung function relationship has been relatively understudied in China, and to our knowledge this is the first study to identify transportation use and indoor air pollution as two potential mediators of this relationship in any country. We believe that this study, in conjunction with others, may have important public health implications. Reducing socioeconomic inequalities in pulmonary health might be approached using two frameworks. First, we can look for mediating factors that produce worse pulmonary health in disadvantaged populations, and then consider targeting those exposures. For instance, public health programs that attempt to address unsafe home cooking fuel use, expand commuting options, modify smoking habits, or increase fruit and vegetable intake among low SES individuals might (and this is admittedly speculative) help to lessen inequalities in pulmonary health. Second, the fact that SES affects pulmonary health even when accounting for known mediating exposures (as was the case in this study) provides a potential argument for going further upstream, and attenuating disparities in socioeconomic conditions themselves. This study provides some tentative support for both frameworks.

\section{Conclusions}

In conclusion, in this study, we found cross-sectional evidence for strong socioeconomic disparities in lung function in Shanghai that widened with increasing age. These disparities were partially attenuated when controlling for several potentially modifiable risk factors, though much of the socioeconomic gradient in lung function remains unexplained. China - like all nations - contends with significant socioeconomic inequalities in health [40]. Further research is needed to further elucidate the respiratory consequences of these disparities.

\section{Abbreviations \\ $\mathrm{FEV}_{1}$ : forced expiratory volume in one second; FVC: forced vital capacity; SES: socioeconomic status; SHS: second hand smoke.}

\section{Competing interests}

The authors declare that they have no competing interests.

\section{Authors' contributions}

Guarantor: DCC takes responsibility for the content of the manuscript. AWG participated in study design, statistical analysis, and interpretation of results, and was responsible for drafting the manuscript. DCC originated the study concept and design, field collection, advised analyses and interpretation of data, and revised the entire manuscript critically. JQH participated in study design, field collection, and interpretation. LS participated in study design, data collection, field and lab quality control, and interpretation. FYZ participated in data collection, analysis, and interpretation. MSL participated in data analysis and interpretation. All authors read and approved the final manuscript.

\section{Acknowledgments}

Overall study funding

National Institutes of Health (T32 HL116275 and ES000002)

Shanghai Putuo District People's Hospital

\section{By author}

Adam W. Gaffney, MD: National Institutes of Health T32 HL116275

Jing-qing Hang, MD and Feng-ying Zhang, MD: Shanghai Putuo District People's Hospital, Shanghai, China

Mi-Sun Lee, PhD, MPH; Li Su, MS; David C. Christiani, MD, MPH, MS:

National Institutes of Health (ES000002)

The study sponsors (National Institutes of Health and the Putuo People's Hospital) had no role in study design, data collection, analysis, interpretation, manuscript preparation, or in the decision to submit the manuscript for publication.

\section{Author details}

${ }^{1}$ Massachusetts General Hospital, 55 Fruit Street, Boston, MA 02114, USA. ${ }^{2}$ Shanghai Putuo District People's Hospital, Shanghai, China. ${ }^{3}$ Department of Environmental Health, Harvard T.H. Chan School of Public Health, 677 Huntington Ave, Boston, MA 02115, USA. ${ }^{4}$ Harvard Medical School, Boston, MA, USA.

\section{Received: 17 September 2015 Accepted: 19 January 2016 Bमे?}

\section{References}

1. Hegewald MJ, Crapo RO. Socioeconomic status and lung function. Chest. 2007;132(5):1608-14

2. Shohaimi S, Welch A, Bingham S, Luben R, Day N, Wareham N, et al. Area deprivation predicts lung function independently of education and social class. Eur Respir J. 2004;24(1):157-61.

3. Prescott $E$, Lange $P$, Vestbo J. Socioeconomic status, lung function and admission to hospital for COPD: results from the Copenhagen City Heart Study. Eur Respir J. 1999;13(5):1109-14.

4. Welle I, Eide GE, Gulsvik A, Bakke PS. Pulmonary gas exchange and educational level: a community study. Eur Respir J. 2004;23(4):583-8. 
5. Schikowski T, Sugiri D, Reimann V, Pesch B, Ranft U, Kramer U. Contribution of smoking and air pollution exposure in urban areas to social differences in respiratory health. BMC Public Health. 2008;8:179.

6. Tabak C, Spijkerman AM, Verschuren WM, Smit HA. Does educational level influence lung function decline (Doetinchem Cohort Study)? Eur Respir J. 2009;34(4):940-7.

7. Van Sickle D, Magzamen S, Mullahy J. Understanding socioeconomic and racial differences in adult lung function. Am J Respir Crit Care Med. 2011;184(5):521-7

8. Ramsay SE, Whincup PH, Lennon LT, Morris RW, Wannamethee SG. Longitudinal associations of socioeconomic position in childhood and adulthood with decline in lung function over 20 years: results from a population-based cohort of British men. Thorax. 2011;66(12):1058-64.

9. Gray LA, Leyland AH, Benzeval M, Watt GC. Explaining the social patterning of lung function in adulthood at different ages: the roles of childhood precursors, health behaviours and environmental factors. J Epidemiol Community Health. 2013;67(11):905-11.

10. Raju PS, Prasad KV, Ramana YV, Balakrishna N, Murthy KJ. Influence of socioeconomic status on lung function and prediction equations in Indian children. Pediatr Pulmonol. 2005;39(6):528-36.

11. Menezes AM, Dumith SC, Perez-Padilla R, Noal RB, Wehrmeister FC, Martinez-Mesa J, et al. Socioeconomic trajectory from birth to adolescence and lung function: prospective birth cohort study. BMC Public Health. 2011;11:596

12. Gong $P$, Liang S, Carlton EJ, Jiang Q, Wu J, Wang L, et al. Urbanisation and health in China. Lancet. 2012;379(9818):843-52.

13. Yang G, Wang Y, Zeng Y, Gao GF, Liang X, Zhou M, et al. Rapid health transition in China, 1990-2010: findings from the Global Burden of Disease Study 2010. Lancet. 2013;381(9882):1987-2015.

14. Yin P, Zhang M, Li Y, Jiang Y, Zhao W. Prevalence of COPD and its association with socioeconomic status in China: findings from China Chronic Disease Risk Factor Surveillance 2007. BMC Public Health. 2011;11:586

15. Smith M, Li L, Augustyn M, Kurmi O, Chen J, Collins R, et al. Prevalence and correlates of airflow obstruction in 317000 never-smokers in China. Eur Respir J. 2014:44(1):66-77.

16. Zhong N, Wang C, Yao W, Chen P, Kang J, Huang S, et al. Prevalence of chronic obstructive pulmonary disease in China. Am J Respir Crit Care Med. 2007;176(8):753-60.

17. Schunemann HJ, Dorn J, Grant BJ, Winkelstein Jr W, Trevisan M. Pulmonary function is a long-term predictor of mortality in the general population: 29-year follow-up of the Buffalo Health Study. Chest. 2000;118(3):656-64

18. Mannino DM, Buist AS, Petty TL, Enright PL, Redd SC. Lung function and mortality in the United States: data from the First National Health and Nutrition Examination Survey follow up study. Thorax. 2003;58(5):388-93.

19. Lee MS, Hang JQ, Zhang FY, Zheng BY, Su L, Zhao Y, et al. Household solid fuel use and pulmonary function in an urban population in Shanghai. China Occup Environ Med. 2013;70(2):120-5.

20. Lee MS, Hang JQ, Zhang FY, Dai HL, Su L, Christiani DC. In-home solid fuel use and cardiovascular disease: a cross-sectional analysis of the Shanghai Putuo study. Environ Health. 2012;11:18.

21. Gaffney AW, Hang JQ, Lee MS, Su L, Zhang FY, Christiani DC. Commuting mode and pulmonary function in Shanghai, China. Eur Respir J. 2015. doi: 10.1183/13993003.00637-2015. [Epub ahead of print].

22. This statement was prepared by the Committee on Proficiency Standards for Clinical Pulmonary Function Laboratories. Standardization of Spirometry, 1994 Update. American Thoracic Society. Am J Respir Crit Care Med. 1995; 152(3):1107-36.

23. Ramsey BW, Astley SJ, Aitken ML, Burke W, Colin AA, Dorkin HL, et al. Efficacy and safety of short-term administration of aerosolized recombinant human deoxyribonuclease in patients with cystic fibrosis. Am Rev Respir Dis. 1993;148(1):145-51.

24. Amin N, Dozor AJ. Effects of administration of aerosolized recombinant human deoxyribonuclease on resting energy expenditure in patients with cystic fibrosis. Pediatr Pulmonol. 1994;18(3):150-4.

25. Ip MS, Ko FW, Lau AC, Yu WC, Tang KS, Choo K, et al. Updated spirometric reference values for adult Chinese in Hong Kong and implications on clinical utilization. Chest. 2006;129(2):384-92.

26. Shaheen SO, Jameson KA, Syddall HE, Aihie Sayer A, Dennison EM, Cooper $\mathrm{C}$, et al. The relationship of dietary patterns with adult lung function and COPD. Eur Respir J. 2010;36(2):277-84.
27. Sabia S, Shipley M, Elbaz A, Marmot M, Kivimaki M, Kauffmann F, et al. Why does lung function predict mortality? Results from the Whitehall II Cohort Study. Am J Epidemiol. 2010;172(12):1415-23.

28. Wheeler BW, Ben-Shlomo Y. Environmental equity, air quality, socioeconomic status, and respiratory health: a linkage analysis of routine data from the Health Survey for England. J Epidemiol Community Health. 2005;59(11):948-54.

29. Hu G, Zhang X, Chen J, Peto R, Campbell TC, Cassano PA. Dietary vitamin C intake and lung function in rural China. Am J Epidemiol. 1998;148(6):594-9.

30. Tabak C, Smit HA, Rasanen L, Fidanza F, Menotti A, Nissinen A, et al. Dietary factors and pulmonary function: a cross sectional study in middle aged men from three European countries. Thorax. 1999;54(11):1021-6.

31. McFadden E, Luben R, Wareham N, Bingham S, Khaw KT. How far can we explain the social class differential in respiratory function? A cross-sectional population study of 21,991 men and women from EPIC-Norfolk. Eur J Epidemiol. 2009;24(4):193-201.

32. Kaur S, Nieuwenhuijsen MJ, Colvile RN. Fine particulate matter and carbon monoxide exposure concentrations in urban street transport microenvironments. Atmos Environ. 2007:41(23):4781-810

33. Adams HS, Nieuwenhuijsen MJ, Colvile RN, McMullen MA, Khandelwal P. Fine particle (PM2.5) personal exposure levels in transport microenvironments, London, UK. Sci Total Environ. 2001;279(1-3):29-44.

34. Zuurbier M, Hoek G, Oldenwening M, Meliefste $K$, van den Hazel P, Brunekreef $B$. Respiratory effects of commuters' exposure to air pollution in traffic. Epidemiology. 2011;22(2):219-27.

35. Klepczynska Nystrom A, Svartengren M, Grunewald J, Pousette C, Rodin I, Lundin A, et al. Health effects of a subway environment in healthy volunteers. Eur Respir J. 2010;36(2):240-8.

36. Larsson BM, Sehlstedt M, Grunewald J, Skold CM, Lundin A, Blomberg A, et al. Road tunnel air pollution induces bronchoalveolar inflammation in healthy subjects. Eur Respir J. 2007;29(4):699-705.

37. Hancox RJ, Poulton R, Greene JM, McLachlan CR, Pearce MS, Sears MR. Associations between birth weight, early childhood weight gain and adult lung function. Thorax. 2009;64(3):228-32.

38. Islam T, Urman R, Gauderman WJ, Milam J, Lurmann F, Shankardass K, et al. Parental stress increases the detrimental effect of traffic exposure on children's lung function. Am J Respir Crit Care Med. 2011;184(7):822-7.

39. Shankardass K, McConnell R, Jerrett M, Milam J, Richardson J, Berhane K. Parental stress increases the effect of traffic-related air pollution on childhood asthma incidence. Proc Natl Acad Sci U S A. 2009;106(30):12406-11.

40. Tang S, Meng Q, Chen L, Bekedam H, Evans T, Whitehead M. Tackling the challenges to health equity in China. Lancet. 2008;372(9648):1493-501.

\section{Submit your next manuscript to BioMed Central and we will help you at every step:}

- We accept pre-submission inquiries

- Our selector tool helps you to find the most relevant journal

- We provide round the clock customer support

- Convenient online submission

- Thorough peer review

- Inclusion in PubMed and all major indexing services

- Maximum visibility for your research

Submit your manuscript at www.biomedcentral.com/submit 